\title{
Influences of Chinese Traditional Clothing Elements on Modern Clothing Design
}

\author{
Guan Jing ${ }^{1,2}$ \\ ${ }^{1 .}$ Soochow University, Jiangsu, Suzhou215006 \\ 2.Nanjing University Of Finance and Economics, Jiangsu, nanjing210046 \\ 49286268@163.com
}

Keywords: Traditional clothing; Clothing design; Traditional culture; Elements

\begin{abstract}
Chinese traditional clothing contains rich cultural connotations. Today, after the reform and opening up, the clothing industry has developed vigorously. People gradually start pay attention to the local clothing culture, and pursue cultural connotation contained in clothing. For modern designers, the traditional clothing and its cultural background are their creation inspirations during creation phases, and they are also one of the expressive elements preferred by designers at home and abroad. Inheriting traditional clothing culture not only means that it needs us to turn the traditional clothing elements into a symbol, but also needs us to further understand the background and connotations of traditional clothing culture. The work of design without culture is like a gorgeous shell that can't stand the test of history. Only by grasping the inner spirit of traditional clothing culture, abandoning simple piled up work and patch-up work without connotation and learning the modern expressive methods of traditional clothing elements, one can design out the works which can touch people’s heartstrings.
\end{abstract}

\section{Introduction}

Traditional clothing is the clothing which can reflect the traditional clothing culture with Chinese characteristics. Traditional clothing mutually integrates its unique style, comfortable fabrics, bright colors, rich designs and exquisite craft elements to bring people impulsive feelings with visual communication. Traditional clothing culture with Chinese characteristics enjoys its unique artistic features in the style, color, fabrics, decoration and craft, etc. They are profoundly influenced by Chinese traditional culture ideas in the process of their formation and development and finally condensed into the national culture bearing Chinese culture features. These elements are the source of our inspiration in contemporary clothing design, and the use of these Chinese elements can help people to design out the clothing of Chinese style.

\section{The Overview of Chinese Traditional Clothing Elements}

There are many old stories in ancient Chinese civilization, and Chinese traditional elements come up with the tenacity of the Chinese nation's long history. Different times has their unique cultural connotations and form elements, which include Chinese architecture, costumes, traditional Chinese painting and folk art etc., and those cultural connotations and form elements are precious heritage that the ancestors leave to their off-springs. The change of dynasties in the history of our country lead to changes of cultural centers, which finally lead to the appearance Chinese traditional 
elements with different representative features in each historical periods, nations and regions. These elements include: Chinese silk, cloth of brocade, hemp, blue printed fabric; chirpaur, chinese-style chest covering, Chinese tunic suit, collar, surplice, mandarin and split etc.; colorful ethnic colors: such as bright red, green, yellow and blueetc.; Neolithic pottery patterns, bronze patterns in Shang\& Chou dynasties, ancient lacquer ware patterns in Qin and Han dynasties, Buddhism patterns in Wei, Jin, Southern and Northern dynasties and traditional decorative patterns in Tang, Song and Qing dynasties. The above mentioned being extended to our modern life are the essence of Chinese traditional culture which bear the role of inheriting national culture, and is the unique and external characteristics of Chinese nation.

The Aesthetic Performance of Designs. After thousands of years of development and the changes of several dynasties, Chinese traditional clothing of each dynasty has its own unique clothing style and design, but no matter how the style changes, the mainstream concept of traditional Chinese clothing always emphasizes symmetry and balance, and the clothing symmetry can be seen in sleeve, placket, hem, pattern etc. Though there are some other clothing styles being popular in the markets. For example, the asymmetry in the history appeared on the hem of the clothing, the clothing sleeves and placket, and they don't belong to the mainstream.Besides paying attention to the symmetry, balance, Chinese traditional clothing design is particular about proportion, such as the ancient Chinese woman dresses, short jacket unlined upper garment (named $\mathrm{Ru}$ ) matching long dress, and it emphasizes the perfect proportion which hold that "the upper part should be short, the below part should be long”; in Song and Ming dynasties people prefer the collocation of long BeiZi (a kind of dress that girls dress in ancient times) and short skirt, the "long upper part, short below part” ratio perfectly reflects the proportion beauty of the clothing.

The Aesthetic Performance of Colors. Green, white, yellow, red, black, the five colors, form the Chinese traditional color system. They have obvious implied meaning and identification.We will mention the performance of implied meaning next. For example, black stands for that the dark heaven, and yellow stands for the earth at dusk, and black and yellow satnd for the heaven and the earth, and they are mostly used in the Kings' clothing. About the colorific choice of Chinese traditional clothing the yellow and the red which the historical role is prominent perform particularly well. In the late period of the Warring States as a royal color yellow appeared and became the supreme ruler's senior clothing color. People advocate yellow but don't prohibit yellow. Later in the years of Tang Gaozu "putting on the yellow robe” became the sign of imperial throne. It continued to exsit till the collapse of the Qing Dynasty with almost one thousand years. In this way yellow nearly becomes the imperial color of the royal family, and it has considerable strong restraint effect on the Chinese people' s social consciousness.

Compared with the noble characteristics of yellow, red has a certain civilians color. The magenta and scarlet are the important colors among the red series. In Chinese traditional clothing colors red has evoluted from the original noble characteristics to the civilians characteristics. Its evolution has experienced a certain period of time. The original red uses magenta, red, cinnabar to represent. It is the noble officials' clothing color. For example, the ministers wear crimson gauze gown or black gown with crimson edge. But later the scarlet among the red series has become a kind of important color in people's life with a certain civilians' color. Few countries in the world can be marked with a color, and China is probably one of the few countries in the world. As a cultural totem and the spirit home of the Chinese people and, its origins date back to the ancient devout worship of Sun God. China red is the Chinese people's soul. The evolution of red custom records the heart journey of the Chinese people. After the connecting link between the preceding and the following, precipitation, deepening and sublation with several generations, the traditional essence 
gradually changes into the base color of Chinese culture. It is filled with positive emtion of going into the society. And it stands for enthusiasm, aggressive, and unite national characters. In Chinese traditional culture, the exquisite of clothing color in people's minds is more deeply rooted. For example, the Chinese peole show their love on red. In our country giving birth to children is needed to tie the red lines. In chinese zodiac anniversary year, chinese people need to tie a red belt. In Chinese New Year people need to put on red couplets and red paper-cuts. Some peole wear red clothing at festivals, and the red clothing can bring them not only the aesthetic feeling of color, but also the aesthetic feeling of jubilation, positivity, enthusiasm and progress. Many designers combine Chinese red and modern clothing design to embody the application of Chinese traditional clothing elements in modern clothing design.

The Aesthetic Performance of Patterns Implication. Chinese traditional pattern aesthetic reflects its implication to a large extent. People consider more about humanistic beauty and classical beauty contained in the clothing. The pattern implication is clothing culture characteristics in the Ming Dynasty. These patterns may use a certain kind of thing to implicate its goodness and beauty, and may use the voice of a certain kind of thing to express the auspicious words. Therefore, they are called "the auspicious patterns". For example, Pine, bamboo and wintersweet implicate the hree friends of winter. People use pine and crane to implicate the longevity, use the mandarin duck to implicate the couples' happy and harmony marriage life, use the pomegranate to implicate multiple children, and use the phoenix and the peony to implicate riches and honour. What's more, people use the bottle and the quail to stand for the safety, use the box, the lotus, the jade to stand for harmoniousness and satisfication, use the bee to stand for being conferred a rank of nobility, use three teams of halberd in the bottle to stand for flat liters level 3, and use the lotus and the catfish to stand for having a surplus in successive years. The auspicious patterns have the feudal consciousness, but at the same time they reflect the people's yearning and pursuit for a better life. Talking of the auspicious patterns in the Qing Dynasty, "Ding Yi of Three Generations", “Lyre-playing, Chess, Calligraphy and Painting”, “Hylotelephium”, “The Dark Eight Immortals” , "Happiness, Affluence, Longevity and Joy” and other forms appear. The manufacture is delicate and exquisite, and the color stresses the layer variability.

The Aesthetic Performance of Decorative Beauty. Decorative features of Chinese traditional clothing are notable, the commonly. used detail adornments include set, rolling, painting and embroidery, etc. The set and rolling of Chinese traditional costume is said to begin from pre-Qin period. At the beginning, the set and rolling parts are generally appeared in the collar, placket, hem and sleeve etc., which shows as the form of wide edge, and there are also the embroidery and textile decorations on the set and rolling parts. The application of set and rolling adornment methods is closely related with the clothing style. For example, the set and rolling adornment methods in Qin and Han dynasties generally have wide edges, which comply with the plain clothing style of that time. However, in Song and Ming dynasties, the set and rolling adornment mainly apply narrow wedges, which comply with the comely, net and slender clothing style of women in Song and Ming dynasties. By Qing dynasty, set and rolling becomes more complex matching the artistic style of over-elaborate. The edge of clothing and accessories are unexpectedly delicate showing that set, rolling and colored embroidery are major features of women's clothing decoration in Qing dynasty. In Qing dynasty, set and rolling laces are usually on the collar, sleeves, placket, hem and trousers. In many cases, there is wide edge on the wide side, and the wide edge is followed by two narrow edges. In addition to set and rolling, there are techniques such as: embroidery, painting, seam with pearl jade. Three sets and five rollings in early times become popular later, and they are developed into 18 rolls, even the clothes of this orginal material are not very obvious so as to make the 
traditional clothing adornment gimmick come to the peak.

\section{The Integration and Innovation between Chinese Traditional Elements and Clothing Design}

With the strengthening of China's comprehensive national strength, Chinese culture is accepted by more and more countries. In this era of diversification, China should keep both avant-garde clothing elements and national elements. The world needs China, and China can't exist without the diversified world. While our traditional culture attracting more and more attention of the world, it also inevitably endures the impact from foreign cultures. Therefore, only by being open minded, can Chinese traditional culture have the say in the world civilization.

In modern clothing design, through the modern way of thinking and way of life, we combine Chinese traditional cultural elements with modern clothing trend perfectly to interpret national costume design. Besides, the reference, inheritance, improvement, development of the essence of the traditional elements and endowing it a new form will give the design another lasting appeal. To achieve the above effect, people should fully understand traditional Chinese elements. And the fabric, color, design, and technology are important parts of clothing design, so to get a detail understanding of the traditional fabric, color, pattern, process, and to keep innovative are important tasks of contemporary Chinese designers, which are also necessary courses for the designers to work out the clothing with excellent Chinese elements. Here, Lawrence. Xu should be mentioned, because his biggest characteristic is to combine Chinese style with western one, which means completely westernized draping yet with very classical eastern style. The connotations of Chinese traditional culture together with the spirit and temperament of western liberal culture forms a founder of the beautiful myth. Look back Lawrence's red carpet dress, it's not hard to find out that the Chinese element is an eternal theme. "Dream Back to Tang Dynasty”, “Three Variations on Plum Blossom”. Being filled with classic breath, those names send out a full-bodied Oriental color, but carefully taste his works, one would find out that they also sending out rich fashion flavor. This is the unique charm that Chinese element bears in fashion design integration innovation.

Chinese-style clothing gradually becomes popular in recent years. After 10 years of development and efforts, some clothing brands that advocate Chinese style gradually become active in the Chinese clothing stage. In Guangzhou, part of clothing brands based on traditional style lead the fashion trend, such as "plough workshop", "ancient color" etc. Clothes designed by these brands combine natural elements with fashion. On the outside, the use of lines is quite concise. The choice of color, bright and lively colors are preferred by people, and it mainly takes the low-key celadon, the enthusiastic red, the natural brown as the mainstream colors. Those colors are used to break the traditional way of color matching. To get natural and elegant texture, the cotton, the hemp and the $\mathrm{BoYu}$ (a kind of cloth) and other materials are good choices, what's more, different kinds of hand-painted decorative patterns are used on different fabrics. Those patterns include both embroidery, printing and dyeing so as to make the cloth be concise, fashionable, and not lack of natural feeling.

\section{Conclusion}

Chinese traditional culture is an indispensable source of inspiration in fashion design. Putting the traditional elements into fashion design not only helps the native culture to extend itself, but also greatly promotes the cultural exchanges in nationalities. Therefore, we should advocate the national advanced culture, make the Chinese traditional culture achieve the development in the clothing design, use the common language to express Chinese traditional culture essence, and integrate 
Chinese traditional element symbol into the spiritual elements of fashion design to make the national culture spirit and the language of the world integrate into the mainstream of modern clothing design. In this way it achieves the promotion of Chinese culture worldwide, to let more people understand Chinese culture, and finally make Chinese clothing design walk towards the big international stage further and further.

\section{References}

[1] Yu-ting Li. The Application of Traditional Clothing Elements in Modern Clothing Design. Journal of Tsinghua University, 2007.

[2] Zhao Fang. Western Clothes Gradually Influence East. Inner Mongolia Normal University, 2013.

[3] Pei-rong Zhang. The Study on Sani's Traditional Clothing in Shi Ling. Kunming University of Science and Technology, 2013.

[4] Ling-li You. The Application Research of People's Clothing Elements in Liangshan Yi Group on Modern Clothing Design. Zhejiang Science and Tech University, 2014. 